\title{
Saccharomyces boulardii Enhances Rat Intestinal Enzyme Expression by Endoluminal Release of Polyamines
}

\author{
JEAN-PAUL BUTS, NADINE DE KEYSER, AND LAURENCE DE RAEDEMAEKER \\ Division of Pediatric Research, Laboratory of Pediatric Gastroenterology and Nutrition, Faculty \\ of Medicine, Catholic University of Louvain, Brussels, Belgium
}

\section{ABSTrACT}

Saccharomyces boulardii is a yeast widely used in humans for the prevention and treatment of infectious enteritis and Clostridium difficile-associated enterocolopathies. After oral administration to human volunteers or growing rats, $S$. boulardii enhances markedly the expression of intestinal enzymes as well as the production of the polymeric immunoglobulin receptor by mechanisms that remain unknown. We have analyzed the role of the yeast polyamines as potential mediators in the intestinal trophic response. In weanling rats (d 20 to $\mathrm{d} 30$ ), a daily dose of 100 $\mathrm{mg}$ of lyophilized $S$. boulardii produced significant ( $p<$ $0.025)$ increases in sucrase $(157 \%)$ and maltase $(47 \%)$ activities. This dose corresponded to a total oral load of 678 nmol of polyamines per day (spermidine: $376 \pm 32$, spermine: $293 \pm 26$, putrescine: $9.5 \pm 1.4 \mathrm{nmol} / 100 \mathrm{mg}$ ). Spermine, given orally to growing rats at doses nearly equiva-

Saccharomyces boulardii is a thermophilic, nontoxic yeast used in many countries for the treatment of acute infectious enteritis (1), antibiotic-induced gastrointestinal disorders $(2,3)$, and Clostridium difficile-associatedenterocolopathies $(4,5)$. The physiologic impact of the yeast on the gastrointestinal tract of mammals remains largely unknown. In a previous study (6), we have shown that the oral treatment of human volunteers and weaned rats with a lyophilized preparation of $S$. boulardii resulted in marked increases in the specific and total activities of brush-border membrane enzymes without morphologic alteration of the intestinal mucosa.

Subsequently, we found increased secretion of $\operatorname{IgA}$ and of the polymeric immunoglobulin receptor in intestinal fluid and mucosa of rats treated with $S$. boulardii (7). Although these changes may contribute to the explana-

Received December 14, 1993; accepted April 26, 1994

Correspondence and reprint requests: Jean-Paul Buts, M.D., Ph.D., Department of Pediatrics, Division of Pediatric Gastroenterology, Cliniques St-Luc, B-1200 Brussels, Belgium.

Supported by the "Fonds de Recherche Scientifique Médicale" (Grants 9.4524.91-4.4511.92) and by a grant from Biocodex Laboratories, Montrouge, France. lent $(500 \mathrm{nmol})$ to the load of polyamines provided by the yeast $(678 \mathrm{nmol})$, reproduced similar enzymatic changes, including a 2.5 -fold induction of sucrase, and enhanced maltase activity $(+24 \%)$. Spermidine and spermine concentrations measured in the jejunal mucosa of treated rats were increased over matched controls by $21.4 \%$ ( $p<$ 0.005 ) and $21.9 \%$, respectively $(p<0.002)$. After being centrifuged and filtered to discard residual yeast cells, 2-mL samples of jejunal and ileal fluid collected from $S$. boulardii-treated rats by intestinal flushing contained higher levels of spermidine (48 and $60 \%)$ and spermine (150 and $316 \%$ ) than did control rats. Our data indicate that lyophilized $S$. boulardii exerts trophic effects on the small intestine that are likely mediated by the endoluminal release of spermine and spermidine. (Pediatr Res 36: 522-527, 1994)

tion of the beneficial effects of the yeast therapy in certain intestinal disorders, the exact mechanism by which $S$. boulardii exerts trophic effects on the small intestinal mucosa is not elucidated. Preliminary findings $(6,7)$ indicate that the enhanced expression of surface membrane glycoproteins including disaccharidases and secretory component seems unrelated to an increase in cell turnover (7) or to changes in the incorporation rate of enzyme precursors into brush-border membranes (6).

Furthermore, $S$. boulardii does not penetrate into epithelial cells and can produce similar effects on enzyme expression whether given in a viable or killed form (6). Recent experimental evidence (8) demonstrates that viable $S$. boulardii secretes a protease able to inhibit binding of $C$. difficile toxin A to specific intestinal receptors of rat ileum. In a rat duodenal crypt cell line, neutralization by $S$. boulardii of the cellular action of cholera toxin is mediated by a $120-\mathrm{kD}$ protein secreted by the yeast (9). These observations prompted us to question whether endoluminal factors secreted by the yeast or released by its intestinal catabolism could account for the intestinal trophic effects observed. 
Yeast cells, like other prokaryotic and eukaryotic cells, contain variable quantities of polyamines that are regulated critically for the needs of their cellular division and DNA and protein synthesis rates (10). Because the oral administration of spermine or spermidine to infant rats enhances markedly intestinal maturation and enzyme expression $(11,12)$, the objective of our study was to analyze the role of these substances as endoluminal mediators in the trophic intestinal response to $S$. boulardii.

Our experiments aimed 1) to measure by HPLC the production of putrescine, spermine, and spermidine in virgin yeast culture media before and after incubation of $S$. boulardii and the concentration of these substances in the final lyophilized preparation of the yeast; 2 ) to determine the changes in polyamine levels in the jejunal and ileal mucosa and in the endoluminal fluid of growing rats treated with $S$. boulardii; and 3) to determine whether spermine given to suckling and weanling rats at doses equivalent to those measured in yeast cells can reproduce the effects of the yeast on intestinal enzyme expression.

\section{METHODS}

Animal studies. The study was approved by the Animal Welfare Committee of Fonds de Recherche Scientifique Médicale. Litters of Wistar rats were housed in polystyrene cages and acclimatized in an air-conditioned room at $21 \pm 1^{\circ} \mathrm{C}$ with a 12 -h light-dark cycle. Immediately after birth, each litter was reduced to eight pups per mother to equalize conditions of nursing and feeding. During the suckling period, pups remained with their mother and had free access to the nipples. At weaning (d 17), they were weaned onto a solid pelleted diet with free access to water. $S$. boulardii was prepared in a lyophilized form $\left(100 \mathrm{mg}\right.$ per flask, biologic activity $2.9 \times 10^{9}$ viable cells $/ \mathrm{mL}$ ) by the manufacturer (Laboratoires Biocodex, Montrouge, France). As previously reported $(6,7)$, we used a dose of $100 \mathrm{mg}$ of $S$. boulardii per day, corresponding to $1 \mathrm{mg}$ of yeast cells per gram body weight per day. Therefore, $100 \mathrm{mg}$ of lyophilized yeast preparation were freshly dissolved in $1.5 \mathrm{~mL}$ of saline and $0.5 \mathrm{~mL}$ was administered to each rat by gastric intubation three times per day from d 20 to 30 postpartum. Control groups were treated according to the same schedule and received equal volumes of saline instead of yeast cells. Six to 10 animals per group were studied. To optimize the intestinal enzymatic response to different doses of polyamines, spermine was given by gastric intubation to sucklings from d 10 to 14 , because at that time the activity of sucrase and maltase is either very low or virtually absent, whereas lactase activity peaks (13). Spermine was administered in $0.5 \mathrm{~mL}$ of saline at 0,500 , or $1000 \mathrm{nmol} / \mathrm{d}$.

Preparation of tissues. At $0800 \mathrm{~h}$, the rats were killed rapidly by decapitation, and the small intestine from the pylorus to the ileocecal valve was immediately excised. After rinsing it in $0.9 \%$ cold saline, the total length was measured and divided into two equal segments. The proximal half was considered the jejunum and the distal half, the ileum. Each segment was promptly opened lengthwise, and the mucosa was scraped off and weighed. It was thereafter wrapped in Parafilm and frozen in liquid nitrogen until use.

Collection of endoluminal fluid. For the collection of intestinal fluid, jejunal and ileal segments were flushed with $2 \mathrm{~mL}$ of cold $0.9 \%$ saline. The collected fluid was centrifuged twice $(500 \times g, 5 \mathrm{~min})$, and the supernatants were pooled and filtered through a $0.2-\mu \mathrm{m}$ membrane filter (Millipore) to discard yeast cells in suspension. The resultant filtrate was frozen until used for the determination of polyamine concentration.

Culture conditions. S. boulardii were inoculated on yeast liquid nitrogen glucose media (YNBG, DIFCO, Detroit, MI) containing $10 \mathrm{~g}$ of glucose per liter and $0.5 \%$ yeast extract. Incubation was performed at $30^{\circ} \mathrm{C}$ with moderate shaking for a total period of $96 \mathrm{~h}$ including three replication cycles. The final inoculum of the stationary growth phase was standardized up to $2.4 \times 10^{7}$ yeast cells $/ \mathrm{mL}$. For the determination of polyamine production in the media, aliquots of media were taken before and after the incubation period and were compared with virgin medium. Yeast-conditioned media were allowed to sediment for $4 \mathrm{~h}$ at $0^{\circ} \mathrm{C}$, were filtered through a $0.2-\mu \mathrm{m}$ Millipore membrane filter, and then were centrifuged at $500 \times g$ for $15 \mathrm{~min}$ at $0^{\circ} \mathrm{C}$. The supernatants were shown to be devoid of yeast cells and were frozen until use for polyamine measurements.

Enzyme assays. Sucrase and maltase activities were measured in homogenates of jejunal mucosa by the method of Messer and Dalqvist (14) within 1 wk of collection. Activities were expressed in units (micromoles of substrate hydrolyzed per minute at $37^{\circ} \mathrm{C}$ ) per gram of mucosal protein. Protein content in mucosa and intestinal fluid was determined by the Lowry method (15).

Analysis of polyamine concentration. The concentrations of putrescine, spermidine, and spermine in lyophilized preparations of $S$. boulardii, culture media, intestinal mucosa, and samples of endoluminal fluid were quantified by HPLC (Gilson model 306; Gilson mixing chambers, model 811A). The method described by Bontemps et al. (16) was used with some modifications. Briefly, after homogenization $(200 \mathrm{mg}$ of mucosa in $1 \mathrm{~mL}$ of deionized water at $0^{\circ} \mathrm{C}$ ) and appropriate dilution (intestinal liquid vol/vol in water at $0^{\circ} \mathrm{C}$ ), proteins were precipitated by addition to the aliquots of solid sulfosalicylic acid up to a final concentration of $33 \mathrm{mg} / \mathrm{mL}$. Precipitation was allowed to proceed further for $24 \mathrm{~h}$ at $20^{\circ} \mathrm{C}$. After centrifugation at $3000 \mathrm{rpm}$ for $15 \mathrm{~min}$, aliquots of supernatants $(800 \mu \mathrm{L})$ were submitted to the dansylation procedure by adding $100 \mu \mathrm{L}$ of saturated $\mathrm{Na}_{2} \mathrm{CO}_{3}$ and $1 \mathrm{~mL}$ of dansyl chloride solution $(10 \mathrm{mg} / \mathrm{mL}$ acetone). Extraction of dansyl derivates was performed twice with cyclohexane. The organic phase was collected from the two extraction procedures, mixed, and evaporated to dryness (Speed VAC, evaporator). Residues of dansyl derivates were dissolved in $1 \mathrm{~mL}$ of acetonitrile and filtered. Ali- 
quots of $20 \mu \mathrm{L}$ were used for chromatography, and samples were run for $34 \mathrm{~min}$ according to a program of linear gradient including two mobile phases: solvent $\mathrm{A}$ (acetonitrile water, 20:80) and solvent B (acetonitrile pure $100 \%$ ). Each sample was analyzed in duplicate.

Measurements of polyamine concentration were made by comparing on a standard curve the integrated surface area of peaks with areas of dansylated polyamines of known concentration.

Statistical methods. Statistical analyses were performed using analysis of variance and $t$ test. If these methods were not appropriate, differences between means were tested for statistical significance by the Mann-Whitney $U$ test (nonparametric). Differences between means were considered significant for $p<0.05$.

\section{RESULTS}

Polyamines in S. boulardii. During the incubation period of yeast cells $(96 \mathrm{~h})$, there was virtually no release of spermidine or spermine in the yeast liquid culture media. Only traces of putrescine could be detected; the amount was doubled after $96 \mathrm{~h}$ of culture (putrescine before incubation: $0.096 \pm 0.05 \mathrm{nmol} / \mathrm{mL}$ medium; after incubation: $0.219 \pm 0.01 \mathrm{nmol} / \mathrm{mL}$ medium). Table 1 details the concentrations of putrescine, spermidine, and spermine measured by HPLC in the final lyophilized preparation of $S$. boulardii. Results are expressed per milligram of lyophilized yeast cells and per milligram of yeast cell protein. The total amount of polyamines measured was $6.79 \mathrm{nmol} / \mathrm{mg}$ lyophilizate including mainly spermidine $(55.4 \%)$ and spermine $(43.6 \%)$ with very low proportions of putrescine $(1.4 \%)$.

Intestinal enzyme responses to $S$. boulardii and spermine. As expected, the oral administration of $S$. boulardii $(100$ $\mathrm{mg} / \mathrm{d}$ ) to weanling rats (d 20 to 30 ) produced significant increases in the specific activity of sucrase $(157 \%, p<$ 0.0025 versus controls) and maltase $(47.5 \%, p<0.025)$ (Fig. 1). Changes in the total activities of these enzymes paralleled the changes in the specific activities because protein content was equivalent in the jejunal mucosa of treated rats (protein: $107 \pm 4 \mathrm{mg} / \mathrm{g}$ mucosa) and controls (108 $\pm 2.3 \mathrm{mg} / \mathrm{g}$ mucosa). The discovery of significant amounts of spermidine $(376 \mathrm{nmol} / 100 \mathrm{mg})$ and spermine $(290 \mathrm{nmol} / 100 \mathrm{mg})$ in the lyophilized preparation prompted us to analyze the intestinal enzymatic response to the daily oral administration of spermine given at doses nearly equivalent to $(500 \mathrm{nmol})$ or 2 times higher $(1000$

Table 1. Concentration of polyamines in lyophilized preparations of $S$. boulardii $(S . b .)^{*}$

\begin{tabular}{lcc}
\hline & $\begin{array}{c}S . b .(\mathrm{nmol} / \mathrm{mg}) \\
(n=8)\end{array}$ & $\begin{array}{c}S . b . \\
(\mathrm{nmol} / \mathrm{mg} \text { protein }) \\
(n=8)\end{array}$ \\
\hline Putrescine & $0.095 \pm 0.014$ & $0.28 \pm 0.05$ \\
Spermidine & $3.766 \pm 0.328$ & $10.9 \pm 0.84$ \\
Spermine & $2.930 \pm 0.268$ & $8.42 \pm 0.67$ \\
Total & 6.79 & 19.6 \\
\hline$* n=$ number of individual samples analyzed. Values are mean \pm
\end{tabular}
SD.

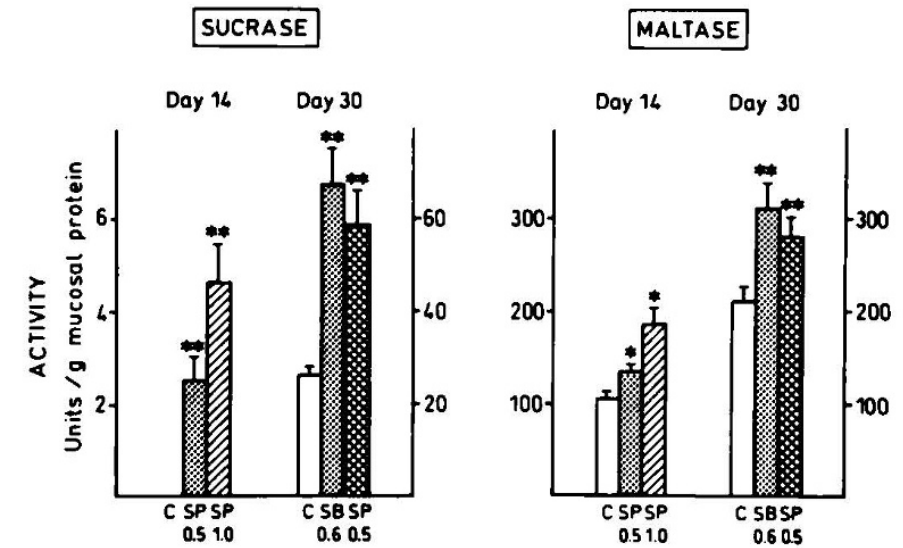

Figure 1. Comparative changes in the specific activity of sucrase and maltase induced by the oral administration of spermine ( $S P 0.5$ and 1.0 $\mu \mathrm{mol} / \mathrm{d}$, respectively) or of lyophilized $S$. boulardii $(S B \quad 0.6: 100 \mathrm{mg} / \mathrm{d}$ corresponding to $0.37 \mu \mathrm{mol}$ of spermidine and $0.29 \mu \mathrm{mol}$ of spermine). Each value represents the mean \pm SEM of individual measurements obtained from eight rats. Note absence of value depicted for sucrase in controls $(C)$ corresponding to virtually no activity detected at $\mathrm{d} 14 .{ }^{*}, p$ $<0.05$ vs controls; ${ }^{* *}, p<0.01$ vs controls.

nmol) than the total supply in spermine and spermidine provided by $100 \mathrm{mg}$ of yeast cells. The results are illustrated in Figure 1. Compared with controls, sucklings treated with $500 \mathrm{nmol}$ of spermine (spermine 0.5 ) presented a significant induction of sucrase $(2.5$-fold increase) and an enhanced maltase activity $(+24 \%, p<$ 0.05 ). In response to $1000 \mathrm{nmol}$ of spermine (spermine 1.0 ), the stimulation of the enzyme activities was proportionally greater, including a 4.6-fold increase in sucrase and a $70 \%$ increase in maltase. Similarly, weanling rats treated with spermine (spermine 0.5) exhibited higher sucrase and maltase activities than controls. Again, the changes in total enzyme activities were identical with the changes in specific enzyme activities (data not shown).

Polyamines in intestinal mucosa. The concentrations in putrescine, spermidine, and spermine measured by HPLC in the jejunal mucosa of rats treated with $S$. boulardii $(100 \mathrm{mg} / \mathrm{d})$ or with saline are detailed in Table 2 . Compared with matched controls, the concentrations in spermidine and spermine were significantly increased by $21.4 \%$ and $21.9 \%$, respectively, in the jejunal mucosa of treated rats, whereas changes in mucosal putrescine and protein concentrations were minor and nonsignificant.

Polyamines in endoluminal fluid. Diluted jejunal and ileal fluids collected from rats treated with $S$. boulardii by intestinal flushing were centrifuged and filtered to discard residual yeast cells remaining in suspension. Microscopic examination and enzyme assays revealed that the filtrates contained no yeast cells. As shown in Table 3, the concentrations in spermidine and spermine $(\mathrm{nmol} / \mathrm{mg}$ protein), measured in the jejunal samples of fluid collected from $S$. boulardii-treated rats, were increased by $48 \%$ and $316 \%$, respectively, over the control levels, whereas the concentration of putrescine remained practically unchanged. Similarly, in the ileal fluid collected from treated rats, spermidine and spermine concentrations 
Table 2. Changes in putrescine, spermidine, and spermine levels measured in jejunal mucosa of rats treated with $S$. boulardii (S.b.) $(100 \mathrm{mg} / \mathrm{d})$ or with saline (controls)*

\begin{tabular}{|c|c|c|c|c|}
\hline & $\begin{array}{l}\text { Controls } \\
(n=10)\end{array}$ & $\begin{array}{l}\text { S.b. treated } \\
(n=10)\end{array}$ & $p^{\dagger}$ & $\Delta(\%) \ddagger$ \\
\hline Putrescine & $1.21 \pm 0.28$ & $1.30 \pm 0.22$ & NS & +7.4 \\
\hline Spermidine & $13.57 \pm 2.05$ & $16.48 \pm 2.11$ & $<0.005$ & +21.4 \\
\hline Spermine & $7.52 \pm 1.10$ & $9.17 \pm 1.01$ & $<0.002$ & +21.9 \\
\hline Ratio spermidine/spermine & 1.80 & 1.79 & NS & \\
\hline Proteins (mg/g mucosa) & $96.1 \pm 6.4$ & $96.5 \pm 5.12$ & NS & +0.34 \\
\hline
\end{tabular}

$* n=$ Number of animals studied. All concentrations are expressed in $\mathrm{nmol} / \mathrm{mg}$ mucosal protein. Data are mean $\pm \mathrm{SD}$.

$\dagger$ Probability vs control group.

$¥$ Variations in percent $v s$ control group.

exceeded by 60 and $150 \%$, respectively, the concentrations of these substances measured in the control group (Table 3).

Although in the ileal samples of treated rats the mean level of putrescine was $33 \%$ higher than in controls, the difference was not statistically significant. Differences in polyamine levels between $S$. boulardii-treated rats and controls were similar whether their concentrations were expressed in $\mathrm{nmol} / \mathrm{mg}$ of protein (Table 3 ) or in $\mathrm{nmol} / \mathrm{mL}$ of collected fluid (Table 4).

\section{DISCUSSION}

Several experiments including the present one provide convincing evidence that $S$. boulardii, when given orally to human volunteers or to adult rats, exerts trophic effects on the small intestine consisting of increases in microvillous enzyme activities (6), mucosal DNA content (7), cellular concentration of polymeric immunoglobulin receptor, and endoluminal secretion of secretory $\operatorname{IgA}(7)$. The mechanism(s) by which yeast cells stimulate the production of intestinal glycoproteins whose intracellular biogenesis and physiologic functions are quite different has not yet been elucidated. Because $S$. boulardii does not penetrate into enterocytes and can produce similar trophic effects whether given in a viable or in a killed form (6), we have questioned the possible influence of endoluminal trophic factors secreted by the yeast or released as a result of its catabolism (17). Our measurements by HPLC revealed substantial amounts of polyamines totaling $673 \mathrm{nmol} / 100 \mathrm{mg}$ in the lyophilized prep- aration, mainly spermidine $(55 \%)$ and spermine $(43 \%)$ with negligible amounts of putrescine $(1.4 \%)$. Theoretically, such amounts of polyamines are able to influence intestinal enzyme expression. Indeed, it has been shown that marked changes in intestinal disaccharidase and aminopeptidase activities occur in infant rat small intestine in response to oral supplies in spermine or in spermidine equivalent to $1000 \mathrm{nmol} / \mathrm{d}$ (12). The comparison presented here between the effects of $100 \mathrm{mg}$ of lyophilized $S$. boulardii $(673 \mathrm{nmol}$ of polyamines) and $500 \mathrm{nmol}$ of spermine given orally to suckling and weanling rats revealed similar patterns of enzymatic response. As previously noted (12), the stimulation of sucrase and maltase by oral spermine is dose dependent, is more sensitive than for other microvillous enzymes (lactase, aminopeptidase), and becomes detectable for doses of spermine exceeding $250 \mathrm{nmol} / \mathrm{d}$. Both $S$. boulardii (7) and oral spermine (12) have been shown to enhance significantly the intestinal production of the polymeric immunoglobulin receptor in weanling rats treated from d 20 to 30 postpartum.

Besides changes in enzyme activities, oral treatment with $S$. boulardii resulted in parallel changes in polyamine concentrations in both intestinal mucosa and endoluminal fluid. The variations in the three polyamine levels measured in the intestinal mucosa were proportional to their concentration measured in the yeast lyophilized preparation. Spermidine and spermine that represented 55 and $44 \%$, respectively, of the total amount of polyamines supplied by $S$. boulardii increased in the same

Table 3. Polyamine concentration in jejunal and ileal fluid of rats treated with $S$. boulardii (S.b.) or saline*

\begin{tabular}{|c|c|c|c|c|}
\hline & $\begin{array}{c}\text { Controls } \\
(\mathrm{nmol} / \mathrm{mg} \text { protein }) \\
(n=6)\end{array}$ & $\begin{array}{c}\text { S.b. treated } \\
\text { (nmol/mg protein) } \\
(n=6)\end{array}$ & $p^{\dagger}$ & $\Delta(\%) \ddagger$ \\
\hline \multicolumn{5}{|l|}{ Jejunal fluid } \\
\hline Putrescine & $4.0 \pm 1.2$ & $4.3 \pm 3.6$ & NS & +7 \\
\hline Spermidine & $6.8 \pm 2.6$ & $10.1 \pm 3.1$ & $<0.05$ & +48.5 \\
\hline Spermine & $0.6 \pm 0.5$ & $2.5 \pm 1.1$ & $<0.05$ & +316 \\
\hline \multicolumn{5}{|l|}{ Ileal fluid } \\
\hline Putrescine & $7.2 \pm 1.2$ & $9.6 \pm 6.8$ & NS & +33.3 \\
\hline Spermidine & $12.5 \pm 1.7$ & $20.1 \pm 5.4$ & $<0.005$ & +60.8 \\
\hline Spermine & $1.4 \pm 0.2$ & $3.5 \pm 0.9$ & $<0.005$ & +150 \\
\hline
\end{tabular}

$* n=$ Number of animals studied. All concentrations are expressed in $n m o l / m g$ protein. Data are mean \pm SD.

$\dagger$ Probability $v s$ controls.

$\ddagger$ Difference in percent $v s$ control group. 
Table 4. Polyamine levels measured in $2 \mathrm{~mL}$ of jejunal and ileal samples collected by intestinal flushing from rats treated with $S$. boulardii (S.b.) or saline*

\begin{tabular}{|c|c|c|c|c|}
\hline & $\begin{array}{c}\text { Controls } \\
(\mathrm{nmol} / \mathrm{mL}) \\
(n=6)\end{array}$ & $\begin{array}{l}\text { S.b. treated } \\
(\mathrm{nmol} / \mathrm{ml}) \\
(n=6)\end{array}$ & $p^{\dagger}$ & $\Delta(\%) \ddagger$ \\
\hline \multicolumn{5}{|l|}{ Jejunal fluid } \\
\hline Putrescine & $6.2 \pm 1.7$ & $7.1 \pm 3.6$ & NS & +14 \\
\hline Spermidine & $10.5 \pm 4.6$ & $15.0 \pm 5.6$ & $<0.05$ & +42 \\
\hline Spermine & $0.9 \pm 0.8$ & $4.2 \pm 3.0$ & $<0.05$ & 4.6-fold \\
\hline \multicolumn{5}{|l|}{ Ileal fluid } \\
\hline Putrescine & $16.1 \pm 2.6$ & $22.2 \pm 15.6$ & NS & +37 \\
\hline Spermidine & $28.2 \pm 8.5$ & $45.9 \pm 14.4$ & $<0.0002$ & +62.7 \\
\hline Spermine & $3.1 \pm 0.4$ & $7.8 \pm 2.2$ & $<0.0005$ & 2.5 -fold \\
\hline
\end{tabular}

${ }^{*} n=$ Number of animals studied. All values are expressed in $\mathrm{nmol} / \mathrm{mL}$ collected fluid. Data are mean $\pm \mathrm{SD}$.

$\dagger$ Probability vs controls.

$\ddagger$ Difference in percent $v s$ controls.

proportions in the intestinal mucosa (21.4 and 21.9\%). In concordance with the negligible amount of putrescine provided by the yeast $(1.4 \%)$, mucosal putrescine levels varied very little and were unaffected by the oral treatment. Also, the ratio of spermidine to spermine was equivalent in treated rats (1.79) and controls (1.80). These data are in agreement with those of Kelly et al. (19), who found a spermidine/spermine ratio of 1.60 in the small intestinal mucosa of infant pigs at the age of $3 \mathrm{wk}$.

Experimental evidence indicates that the uptake of endoluminal polyamines by brush-border membrane vesicles is a selective and saturable absorptive process dependent to a large extent on their endoluminal concentration (19-22). In agreement with our data, Dufour et al. (11) have reported a $40 \%$ increase in mucosal spermidine concentration in infant rats after an oral load of $3000 \mathrm{nmol}$ of this substance.

In samples of jejunal and ileal fluid collected by intestinal flushing from $S$. boulardii-treated rats, spermidine and spermine concentrations were increased by 48 to $316 \%$ over controls, whereas changes in putrescine levels were not significant. Because endoluminal polyamines (especially putrescine) originate from several sources including food $(19,23)$, intestinal secretions, and microbial flora (24), variations in concentration were much greater in the gut lumen than in mucosa. However, when the amounts of polyamines provided by $S$. boulardii cells (Table 1) were compared with the concentration of these substances measured in samples of jejunal and ileal fluid (Table 3 and 4), it appeared that changes in endoluminal putrescine could not result from $S$. boulardii treatment but rather from the metabolic activity of the intestinal flora. Indeed, the amount of putrescine recovered in 2 $\mathrm{mL}$ of collected fluid represented at the jejunal level $146 \%$ of the yeast putrescine content and at the ileal level $461 \%$. The same comparison for the two other polyamines revealed recovery percentages of 7.9 to $24 \%$ for spermidine and 2.8 to $5.4 \%$ for spermine.

Taken together our data indicate that, at the dose used, lyophilized $S$. boulardii exerts trophic effects on the small intestinal mucosa that are likely mediated by the release of spermidine and spermine in the endoluminal compart- ment. These substances could be released by the yeast intestinal catabolism rather than secreted by viable cells during their transit. Indeed, only traces of putrescine were detected in the yeast culture media after $96 \mathrm{~h}$ without evidence of spermidine and spermine secretion in the media. Further support for our conclusion is provided by two observations: 1 ) less than $3 \%$ of the oral dose of yeast cells is recovered in stools in a viable form, indicating that progressive endoluminal catabolism occurs during the intestinal transit (24); and 2) microfloraderived polyamines can modulate mucosal thickness, causing even intestinal obstruction by excessive bowel hypertrophy (25).

In view of the well-known physiologic effects of exogenous polyamines on cell maturation, enzyme expression, membrane transport mechanisms, and epithelial cell renewal, the present data showing substantial concentrations of spermine and spermidine in $S$. boulardii could have important clinical implications. Because $S$. boulardii use is indicated in acute enteropathies and gastrointestinal microflora disturbances, rational use of the yeast requires that potential trophic effects for the prevention of chronic persistent or protracted enteropathies be further investigated in infants and children.

Acknowledgments. The authors thank Paul Bernasconi and Bernard Hublot for critical review of the manuscript. D. Vermeulen is acknowledged for preparation of the manuscript.

\section{REFERENCES}

1. McFarland LV, Bernasconi P 1993 Saccharomyces boulardii: a review of an innovative biotherapeutic agent. Microbiol Ecol Health Dis 6:157-171

2. Toothaker RD, Elmer GW 1984 Prevention of clindamycin-induced mortality in hamsters by Saccharomyces boulardii. Antimicrob Agents Chemother 26:552-556

3. Surawicz CM, Elmer GW, Speelman P, McFarland LV, Chinn J, Van Belle G 1989 Prevention of antibiotic-associated diarrhea by Saccharomyces boulardii: a prospective study. Gastroenterology 96:981-988

4. Buts JP, Corthier G, Delmee M 1993 Saccharomyces boulardii for Clostridium difficile-associated enteropathies in infants. J Pediatr Gastroenterol Nutr $16: 419-425$

5. Surawicz CM, McFarland LV, Elmer GW, Chinn J 1989 Treatment of recurrent Clostridium difficile colitis with vancomycin and Saccharomyces boulardii. Am J Gastroenterol 84:1285-1287 
6. Buts JP, Bernasconi P, Van Craynest MP, Maldague P, De Meyer R 1986 Response of human and rat small intestinal mucosa to oral administration of Saccharomyces boulardii. Pediatr Res 20:192-196

7. Buts JP, Bernasconi P, Vaerman JP, Dive C 1990 Stimulation of secretory IgA and secretory component of immunoglobulins in small intestine of rats treated with Saccharomyces boulardii. Dig Dis Sci 35:251-256

8. Pothoulakis C, Kelly CP, Joski MA, Gao N, O'Keane CJ, Casta Gliuolo I, Lamont JT 1993 Saccharomyces boulardii inhibits Clostridium difficile toxin A binding and enterotoxicity in rat ileum. Gastroenterology 104:1108-1115

9. Czerucka D, Roux I, Rampal P 1994 Saccharomyces boulardii inhibits secretagogue-mediated cAMP induction in cultured intestinal cells. Gastroenterology 106:65-72

10. Tabor CW, Tabor H 1984 Polyamines. Ann Rev Biochem 53:749-790

11. Dufour C, Dandrifosse G, Forget P, Vermesse F, Romain N, Lepoint P 1988 Spermine and spermidine induce intestinal maturation in the rat. Gastroenterology 95:112-116

12. Buts JP, De Keyser N, Kolanowski J, Sokal E, Van Hoof F 1993 Maturation of villus and crypt cell functions in rat small intestine: role of dietary polyamines. Dig Dis Sci 38:1091-1098

13. Henning SJ 1981 Postnatal development: coordination of feeding, digestion and metabolism. Am J Physiol 241:G199-G214

14. Messer M, Dahlqvist A 1966 A one step ultramicromethod for the assay of intestinal disaccharidases. Anal Biochem 14:376-392

15. Lowry OH, Rosebrough WJ, Farr AL, Randall RJ 1951 Protein measuremen with the Folin phenol reagent. J Biol Chem 193:265-275

16. Bontemps J, Laschet J, Dandrifosse G 1984 Analysis of dansyl derivates of diand polyamines in mouse brain, human serum and duodenal biopsy specimens by high-performance liquid chromatography on a standard reverse-phase column. J Chromatogr 311:59-67

17. Miret JJ, Solari AJ, Barderi PA, Goldenberg SH 1992 Polyamines and cell wall organization in Saccharomyces cerevisiae. Yeast 8:1033-1041

18. Georges P, Dandrifosse G, Vermesse F, Forget P, Deloyer P, Romain N 1990 Reversibility of spermine-induced intestinal maturation in the rat. Dig Dis Sci 35:1528-1536

19. Kelly D, King TP, Brown DS, McFadyen M 1991 Polyamine profiles of porcine milk and of intestinal tissue of pigs during suckling. Reprod Nutr Dev 31:73-80

20. Kobayashi M, Iseki K, Saitoh H, Miyazaki K 1992 Uptake characteristics of polyamines into rat intestinal brush border membrane. Biochim Biophys Acta 1105:177-183

21. Iseki K, Kobayashi M, Miyazaki K 1991 Spermine uptake by rat brush border membrane vesicles. Biochim Biophys Acta 1068:105-110

22. Kumagai J, Johnson LR 1988 Characteristics of putrescine uptake in isolated rat enterocytes. Am J Physiol 254:G81-G86

23. Bardocz S, Brown DS, Grant G, Pusztai A 1990 Luminal and basolateral polyamine uptake by rat small intestine stimulated to grow by phaseolus vulgaris lectin PHA in vivo. Biochem Biophys Acta 1034:46-52

24. Boddy AV, Elmer GW, McFarland LV, Levy RH 1991 Influence of antibiotics on the recovery and kinetics of Saccharomyces boulardii in rat. Pharm Res 8:796-800

25. Osbourne DL, Seidel ER 1989 Microflora derived polyamines modulate obstruction-induced colonic mucosa hypertrophy. Am J Physiol 256:G1049_ G1057 